\title{
AQP3 Facilitates Proliferation and Adipogenic Differentiation of Porcine Intramuscular Adipocytes
}

\author{
Xiaoyu Wang, Jing Yang, Ying Yao, Xin'E Shi, Gongshe Yang $\$ and Xiao Li * (1) \\ Key Laboratory of Animal Genetics, Breeding and Reproduction of Shaanxi Province, College of Animal Science \\ and Technology, Northwest A \& F University, Yangling 712100, China; wangxy067@163.com (X.W.); \\ yangjing@nwsuaf.edu.cn (J.Y.); yaoying@nwsuaf.edu.cn (Y.Y.); xineshi@163.com (X.S.); \\ gsyang999@hotmail.com (G.Y.) \\ * Correspondence: nice.lixiao@gmail.com; Tel.: +86-29-870-81531
}

Received: 19 March 2020; Accepted: 13 April 2020; Published: 22 April 2020

\begin{abstract}
The meat quality of animal products is closely related to the intramuscular fat content. Aquaglyceroporin (AQP) defines a class of water/glycerol channels that primarily facilitate the passive transport of glycerol and water across biological membranes. In this study, the AQP3 protein of the AQP family was mainly studied in the adipogenic function of intramuscular adipocytes in pigs. Here, we found that AQP3 was increased at both mRNA and protein levels upon adipogenic stimuli in porcine intramuscular adipocytes in vitro. Western blot results showed knockdown of AQP3 by siRNA significantly suppressed the expression of adipogenic genes (PPAR $\gamma, \mathrm{aP2}$, etc.), repressed Akt phosphorylation, as well as reducing lipid accumulation. Furthermore, deletion of AQP3 by siRNA significantly downregulated expression of cell cycle genes (cyclin D, E), and decreased the number of EdU-positive cells as well as cell viability. Collectively, our data indicate that AQP3 is of great importance in both adipogenic differentiation and proliferation in intramuscular adipocytes, providing a potential target for modulating fat infiltration in skeletal muscles.
\end{abstract}

Keywords: AQP3; pig; intramuscular fat; adipogenesis; proliferation

\section{Introduction}

Ectopic fat deposition in skeletal muscle has attracted increasing attention in recent decades. In humans, excessive fat accumulation in skeletal muscle always represents muscle weakness, myopathy, and metabolic diseases such as obesity, diabetes, coronary heart disease, etc. [1]. Conversely, in livestock animals (cattle, pig, sheep, etc.), distribution of intramuscular fat (IMF), referred to as marbling by customers, is closely related to meat quality, and a moderate increase in IMF benefits the taste and flavor of meat products [2]. The high content of intramuscular fat can increase the tenderness and flavor of pork [3]. Marbling develops either by an increase in adipocyte number, or adipocyte volume, or both. Thus, the molecular mechanisms underlying the proliferation and differentiation of intramuscular adipocytes deserve further study.

Aquaglyceroporin (AQP) refers to a subgroup of aquaporins that conduct glycerol, water, and other small polar solutes in response to osmotic gradients. Glycerol is a necessary constituent of triglyceride (TG) backbones, and glycerol uptake together with release across the plasma membrane are two key steps in triglyceride synthesis (lipogenesis) and hydrolysis (lipolysis) in adipose, liver, and other metabolic organs, thus AQPs have emerged as key players in adipose biology and the development of obesity [4]. In this context, AQP7, the first identified AQP in adipose tissue, has been emerging as an important player in whole-body metabolism and the progress of obesity and diabetes [5]. In recent studies, expression of $\mathrm{AQP} 3, \mathrm{AQP9}, \mathrm{AQP10}$, and $\mathrm{AQP11}$ has been detected in cultured adipocytes and adipose tissues [6-8]. Studies have shown that AQP3 can promote the transport of cellular glycerol 
and has affinity for glycerol [9]. AQP3 has been reported to regulate PPAR $\alpha$ by adiponectin in hepatic stellate cells (HSC) [10]. The classical secretion factor, leptin, of adipocytes can improve systemic obesity and fatty liver in mice via AQP3 in ob/ob mice [11]. AQP3 mRNA expression in human adipose tissue was reported in another study [12]. These signs indicate that AQP3 may also have a regulatory role in IMF.

Our RNA-seq screening revealed that AQP3 [13], in addition to the well-known AQP7, was upregulated during adipogenic differentiation in porcine intramuscular preadipocytes (PIPAs), indicating a potential role of AQP3 in porcine IMF deposition. Work on the MDA-MB-231 breast cancer cell line has shown that knockdown of AQP3 modestly decreases water permeability $(17 \%)$, but markedly decreases glycerol permeability (77\%) [14], indicating AQP3 might be more permeable to glycerol. Currently, the most well-characterized role of AQP3 is the promotion of cancer metastasis, for AQP3 is abnormally escalated in various kinds of cancers [15] and knockdown of the AQP3 gene could significantly decrease cell proliferation, and increase cell death or apoptosis in cancer cells $[14,16,17]$. In addition, AQP3 deficiency can cause proliferation disorders and metabolic inhibition in gastric cancer cells [18]. More interestingly, another study showed that AQP3 in gastric cancer cells caused apoptosis in gastric cancer cells by downregulating cellular glycerol intake and inhibiting downstream adipogenesis [19]. These data encouraged us to explore the effects of AQP3 on adipogenic differentiation, lipid deposition, and proliferation, using porcine intramuscular preadipocytes as a model.

\section{Materials and Methods}

\subsection{Animal Care}

Piglets in our study were obtained from the experimental plot of Northwest A\&F University (Yangling, China). Pigs were reared under standard light and temperature conditions and allowed food and water ad libitum. This project was approved by the Institutional Animal Care and Use Committee of Northwest A\&F University.

\subsection{Cell Culture}

Porcine intramuscular preadipocytes were isolated from the longissimus dorsi muscle of 3-day-old piglets as previously described [20]. The specific method was as follows: LD (longissimus dorsi) muscles were quickly excised, rinsed twice in sterile pre-cooled phosphate-buffered saline (PBS), and then cut into $1 \mathrm{~mm}^{3}$ sections. Muscle fragments were incubated in Dulbecco's Modified Eagle's Medium/F12 (DMEM/F12; Hyclone, Logan, UT, USA) containing $0.1 \%$ I type collagenase (270 U/mg; Gibco, Carlsbad, CA) for $1.5 \mathrm{~h}$ in a $37^{\circ} \mathrm{C}$ water bath, with continuous shaking. The products were then sequentially passed through a 70 mesh $(212 \mu \mathrm{m})$ and then a 200 mesh $(75 \mu \mathrm{m})$ to obtain single cells. The cells were seeded in a dish with DMEM/F12 medium containing 10\% fetal bovine serum (Gibco, Grand Island, NY, USA). After $2 \mathrm{~h}$, we changed the medium to keep only adherent cells. In the proliferating stage, the primary preadipocytes were cultured in DMEM/F12 (Gibco, Grand Island, NY, USA) containing 10\% FBS (Invitrogen, Carlsbad, CA, USA).

To induce adipogenic differentiation, when cells achieved $100 \%$ confluence, a mixture containing $10 \% \mathrm{FBS}, 5 \mu \mathrm{g} / \mathrm{mL}$ ( $872 \mathrm{nM}$ ) insulin, $1 \mu \mathrm{M}$ dexamethasone (DEX), and $0.5 \mathrm{mM}$ isobutyl methylxanthine (IBMX; Sigma-Aldrich, St Louis, MO) was used to induce adipogenic differentiation. Two days later, a DMEM/F12 medium containing 10\% fetal bovine serum (FBS) and $5 \mu \mathrm{g} / \mathrm{mL}$ ( $872 \mathrm{nM}$ ) insulin was changed to maintain differentiation.

\subsection{Transfection with siRNA}

Oligonucleotides of AQP3 siRNAs (forward: CCCUUAUCCUCGUGAUGUUTT, reverse: AACAUCACGAGGAUAAGGGTT) and NC (negative control, forward: UUCUCCGAACGUGUCACGUTT, reverse: ACGUGACACGUUCGGAGAATT) were obtained 
from GenePharma (Shanghai, China). Transfection was performed with Lipofectamine ${ }^{\circledR}$ RNAiMAX Reagent (ThermoFisher, Waltham, MA, USA) when cells reached proper confluence (40-50\% for proliferation test, $70-80 \%$ for differentiation test). Negative control and siRNA were added to Opti-MEM (Gibco) and mixed with Lipofectamine ${ }^{\circledR}$ RNAiMAX Reagent. The mixture was allowed to stand for $20 \mathrm{~min}$ before being added to the cell culture plate. The culture medium was replaced after $24 \mathrm{~h}$. The final concentration of siRNA or negative control was $50 \mathrm{nM}$. Cells were changed into fresh growth medium $24 \mathrm{~h}$ post-transfection.

\subsection{RNA Isolation and RT-qPCR}

Total RNA was purified using Trizol (TaKaRa Bio, Inc., Dalian, China) and was subjected to reverse transcription using the PrimeScriptTM RT reagent Kit (TaKaRa Bio, Inc., Dalian, China). A tissue sample $(0.5 \mathrm{~g})$ from a 180-day-old pig was weighed, and high-throughput grinding of the tissue sample in Trizol infiltration extracted total RNA. Each experimental group was subjected to the reverse transcription reaction with $500 \mathrm{ng}$ of RNA. cDNA was subjected to the Multicolor Real-Time PCR detection system (iQ5, Bio-Rad Laboratories, Inc., Hercules, CA, USA) with SYBR Premix Ex TaqTM II kit (TaKaRa Bio, Inc., Dalian, China). The procedure of PCR reaction was pre-denaturation for $5 \mathrm{~min}$, followed by denaturation for $10 \mathrm{~s}$, annealing for $30 \mathrm{~s}$, and extension of $30 \mathrm{~s}$ for 35 cycles. Primers targeting AQP3 [21], PPAR $\gamma$ [22] (peroxisome proliferator activated receptor $\gamma$ ), FABP4 [23] (adipocyte fatty-acid binding protein 4), mGPAT [24] (mitochondrial glycerol-3-phosphate acyltransferase), Perilipin 1 [25], cyclin B [26], and $\beta$-actin [27] were picked out in previous reports. Primers for SCD (stearoyl-CoA desaturase), CD36, C/EBP $\alpha$ (CCAAT/enhancer binding protein $\alpha)$, ELOVL6 (elongase of long-chain fatty acids family), FASN (fatty acid synthetase), ACACA (acetyl-CoA carboxylase), DGAT2 (diacylglycerol O-acyltransferase 2), cyclin E, and cyclin D were designed online (https://www.ncbi.nlm.nih.gov/tools/primer-blast/) and synthesized by Sangon Biotech (Shanghai, China). Relative expression of each gene was calculated using the $2-\Delta \Delta \mathrm{Ct}$ method, using $\beta$-actin as the internal control. Sequences for all primers are shown in Table 1.

Table 1. Primer sequences for real-time qPCR.

\begin{tabular}{|c|c|c|c|}
\hline Gene & Accession Number & Primer Sequences & Production Length/bp \\
\hline AQP3 & NM_001110172.1 & $\begin{array}{l}\text { F: CACCTCCATGGGCTTCAACT } \\
\text { R: TGCCCATTCGCATCTACTCC }\end{array}$ & 278 \\
\hline $\operatorname{PPAR} \gamma$ & NM_214379 & $\begin{array}{l}\text { F: AGGACTACCAAAGTGCCATCAAA } \\
\text { R: GAGGCTTTATCCCCACAGACAC }\end{array}$ & 142 \\
\hline aP2 & NM_001002817.1 & $\begin{array}{l}\text { F: GAGCACCATAACCTTAGATGGA } \\
\text { R: AAATTCTGGTAGCCGTGACA }\end{array}$ & 121 \\
\hline FASN & NM_001099930.1 & $\begin{array}{l}\text { F: GTCCTGCTGAAGCCTAACTC } \\
\text { R: TCCTTGGAACCGTCTGTG }\end{array}$ & 206 \\
\hline SCD & NM_213781.1 & $\begin{array}{l}\text { F: ACAAGAGGCCAAGACAAGTTCC } \\
\text { R: GCTGTAGGGAATGCTGGTTAGTTT }\end{array}$ & 142 \\
\hline ACACA & NM_001114269.1 & $\begin{array}{l}\text { F: TCCCAGTGCAAGCAGTATG } \\
\text { R: TGCCAATCCACACGAAGAC }\end{array}$ & 211 \\
\hline mGPAT & XM_005671462.3 & $\begin{array}{l}\text { F: ACTATCTCCTGCTCACTTTCA } \\
\text { R: CGTCTCATCTAGCCTCCGTC }\end{array}$ & 146 \\
\hline CD36 & NM_001044622.1 & $\begin{array}{l}\text { F: ATCGTGCCTATCCTCTGG } \\
\text { R: CCAGGCCAAGGAGGTTAA }\end{array}$ & 103 \\
\hline C/EBP $\alpha$ & XM_003127015.4 & $\begin{array}{l}\text { F: AACAACTGAGCCGCGAACTG } \\
\text { R: GCTCCGGCAGTCTTGAGAT }\end{array}$ & 181 \\
\hline DGAT2 & NM_001160080.1 & $\begin{array}{l}\text { F: GCAGGTGATCTTTGAGGAGG } \\
\text { R: GCTTGGAGTAGGGCATGAG }\end{array}$ & 140 \\
\hline ELOVL6 & XM_021100708.1 & $\begin{array}{l}\text { F: ACCACATCACTGTGCTCCTC } \\
\text { R: CGAGTGCACGCCATAGTTCA }\end{array}$ & 95 \\
\hline Cyclin B & NM_001170768.1 & $\begin{array}{l}\text { F: AATCCCTTCTTGTGGTTA } \\
\text { R: CTTAGATGTGGCATACTTG }\end{array}$ & 104 \\
\hline Cyclin E & XM_005653265.2 & $\begin{array}{l}\text { F: AGAAGGAAAGGGATGCGAAGG } \\
\text { R: CCAAGGCTGATTGCCACACT }\end{array}$ & 173 \\
\hline Cyclin D & XM_021082686.1 & $\begin{array}{l}\text { F: TACACCGACAACTCCATCCG } \\
\text { R: GAGGGCGGGTTGGAAATGAA }\end{array}$ & 224 \\
\hline$\beta$-actin & XM_021086047.1 & $\begin{array}{l}\text { F: GGACTTCGAGCAGGAGATGG } \\
\text { R: AGGAAGGAGGGCTGGAAGAG }\end{array}$ & 138 \\
\hline
\end{tabular}




\subsection{Western Blot}

Cells were scraped with RIPA (Radio Immunoprecipitation Assay) buffer (Beyotime, Shanghai, China) and lysates were subjected to SDS-PAGE and transferred to the PVDF (Polyvinylidene fluoride, Millipore, Burlington, MA, USA). Polyacrylamide gels were used to separate and mark proteins of different sizes. The proteins were then transferred to a PVDF membrane. Next, the membrane was soaked in $5 \%$ skim milk for $2 \mathrm{~h}$ and then incubated with primary antibodies overnight at $4{ }^{\circ} \mathrm{C}$. After that, membranes were washed in Tris-buffered saline with Tween 20 and subsequently incubated with horseradish peroxidase-conjugated secondary antibodies. Finally, the stripes of target proteins were visualized by the enhanced chemiluminescent substrate (Millipore, MA) and observed using Gel Doc XR System (Bio-Rad). The densities of the brands were analyzed using Image Lab software (Bio-Rad). Target proteins were probed with primary antibodies (anti-AQP3, ab125219, Abcam, 1:1000; PPAR $\gamma$, \#2435, CST, 1:1000; FASN, sc-20140, Santa Cruz, 1:200; FABP4, sc-18661, Santa Cruz, 1:200; Akt, sc-8312, Santa Cruz, 1:200; p-Akt, sc-7985-R, Santa Cruz, 1:200; cyclin D, sc-753, Santa Cruz, 1:500; cyclin E, sc-247, Santa Cruz, 1:500; $\beta$-actin, sc-130656 Santa Cruz, 1:1000).

\subsection{Oil Red O Staining}

The well-differentiated cells were washed twice with PBS and fixed with $4 \%$ paraformaldehyde for $30 \mathrm{~min}$, and then incubated with $1 \%$ filtered Oil Red O solution for $5 \mathrm{~min}$. The stained lipid droplets in the cells were photographed (Nikon TE2000 microscope, Tokyo, Japan). For quantitative analysis, cellular Oil Red O was extracted by isopropanol and optical absorbance was detected at $510 \mathrm{~nm}$.

\subsection{EdU Staining}

EdU assay was conducted with a Cell-Light ${ }^{\mathrm{TM}}$ EdU (5-ethynyl-2'-deoxyuridine) Apollo ${ }^{\circledR} 567$ In Vitro Imaging Kit (RiboBio, Guangzhou, China) as per the manufacturer's instructions. Porcine intramuscular preadipocytes in growth medium were incubated with $50 \mathrm{mM}$ EdU for $2 \mathrm{~h}$, and then fixed by paraformaldehyde. Then cells were labeled with Apollo reaction solution, and the nuclei were stained with Hoechst 33,342 (Thermo Fisher Scientific, Waltham, MA, USA). Cells were visualized using a Nikon TE2000 microscope (Nikon, Tokyo, Japan), and the images were processed with Image J software by the National Institutes of Health (NIH).

\subsection{CCK-8 Assay}

Porcine intramuscular preadipocytes were seeded on a 96-well plate at a density of $1 \times 10^{3}$ per well. Some $24 \mathrm{~h}$ later, 10\% CCK-8 solution (Vazyme, Nanjing, China) was added, and after $4 \mathrm{~h}$ incubation, the absorbance was measured at $490 \mathrm{~nm}$.

\subsection{Statistical Analysis}

All experiments were carried out in triplicate and the results were analyzed by one-way analysis of variance (ANOVA) using SPSS 18 software (SPSS Inc., Chicago, IL, USA). $P<0.05$ was set as statistical significance. Data were presented as mean \pm standard error (SE).

\section{Results}

\subsection{AQP3 Is Upregulated during Adipogenesis}

In order to explore the expression pattern of AQP3 gene in pig adipose tissue and PIPAs we selected 180-day-old pig tissue to test the expression of AQP3. RT-qPCR results showed that AQP3 is highly expressed in adipose tissue (Figure 1A). In subcutaneous adipose tissue of pigs of different ages, the expression of AQP3 reached the highest at 30 days of age, and then began to decline (Figure 1B). 
A

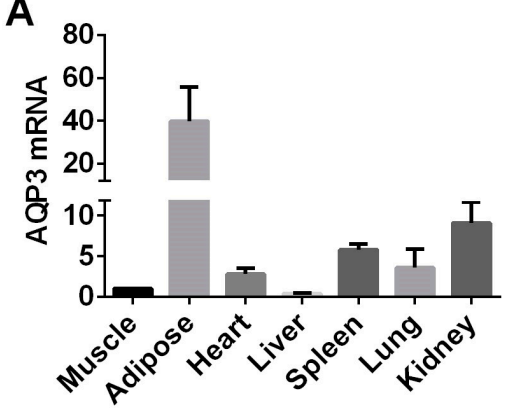

B

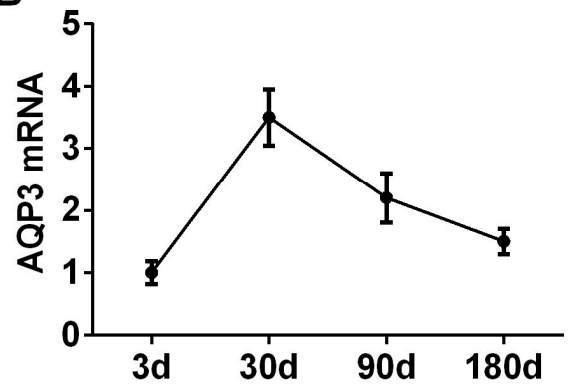

Figure 1. AQP3 expression pattern in pigs in vivo by RT-qPCR. (A) AQP3 pig tissue expression profile. (B) AQP3 expression during pig growth by RT-qPCR. $\beta$-actin was used as internal reference gene. $n=3$.

In in vitro cell culture experiments, transcripts of AQP3 in PIPAs were rapidly increased upon adipogenic stimuli, reached a peak at $4 \mathrm{~d}$ post-differentiation, and then gradually decreased (Figure 2A). The expression of AQP3 proteins showed the same pattern (Figure 2B). For reference, the expression of PPAR $\gamma$ (Figure 2C), FASN (Figure 2D), and aP2 (Figure 2E) throughout the adipogenic process was profiled to represent the efficient differentiation of PIPAs in vitro. The data indicated a promising role of AQP3 in adipogenesis.

A

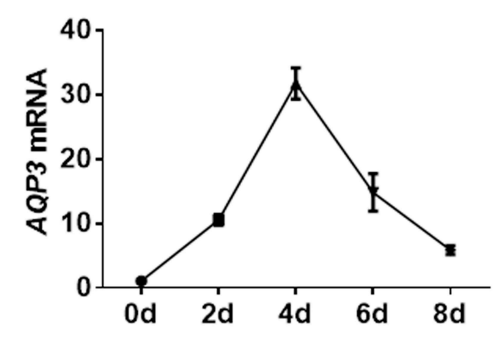

C

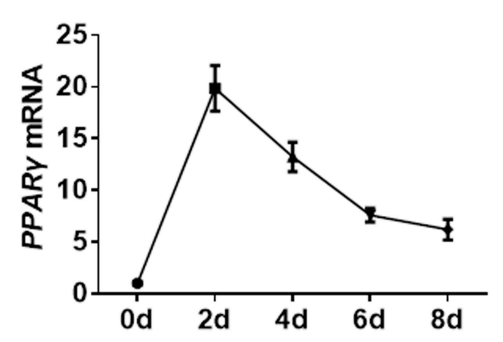

D

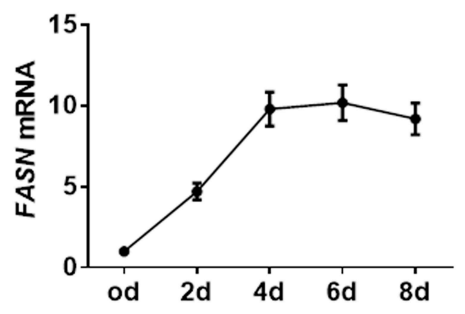

B
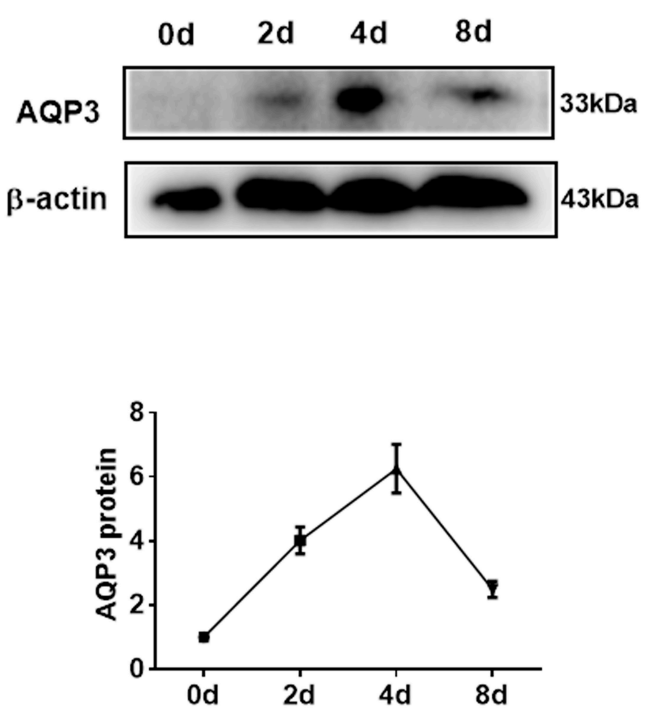

E

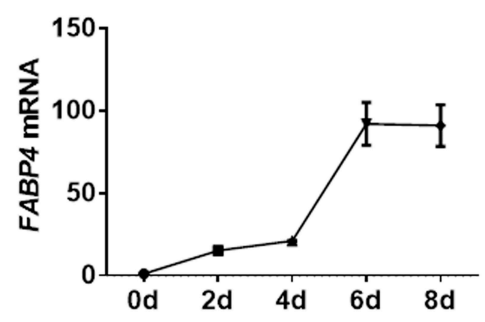

Figure 2. Expression pattern of porcine AQP3 in adipogenesis. The expression of AQP3 during adipogenesis was detected by RT-qPCR (A) and Western blot (B). The expression of PPAR $\gamma(\mathbf{C})$, FASN (D), and aP2 (E) was detected by RT-qPCR. $\beta$-actin was used as internal reference gene. $n=3$. 


\subsection{Knockdown of AQP3 Blunts Adipogenesis}

In view of the rising trend of AQP3 in adipocyte differentiation, siRNAs were employed to explore the role of AQP3 on adipogenic differentiation. Three siRNAs were designed, and only siRNA-1 showed $>70 \%$ knockdown efficiency 24 h post-transfection (Figure $3 \mathrm{~A}$ ), and still significantly reduced AQP3 expression $48 \mathrm{~h}, 4 \mathrm{~d}$, and $8 \mathrm{~d}$ post-differentiation (Figure 3B). Thus, siRNA-1 was used in the following study. RT-qPCR results showed that AQP3 siRNA significantly inhibited the expression of adipogenic markers, such as PPAR $\gamma$, aP2, ACACA, SCD, DGAT2, mGPAT, ELOVL6, and FASN 4d post-differentiation (Figure 3C), and the genes (except PPAR $\gamma$ ) detected above were still significantly downregulated $8 \mathrm{~d}$ post-differentiation (Figure 3D). Western blot results presented the expression of PPAR $\gamma, \mathrm{aP2}$, and FASN at protein levels and phosphorylated Akt (Figure 3E), and the gray level analysis showed that these proteins were significantly decreased (Figure 3F). Oil Red O staining showed that AQP3 siRNA significantly repressed triglyceride accumulation in intramuscular adipocytes (Figure 3G,H). These data indicated that AQP3 was essential for adipogenesis and lipid accumulation in PIPAs.

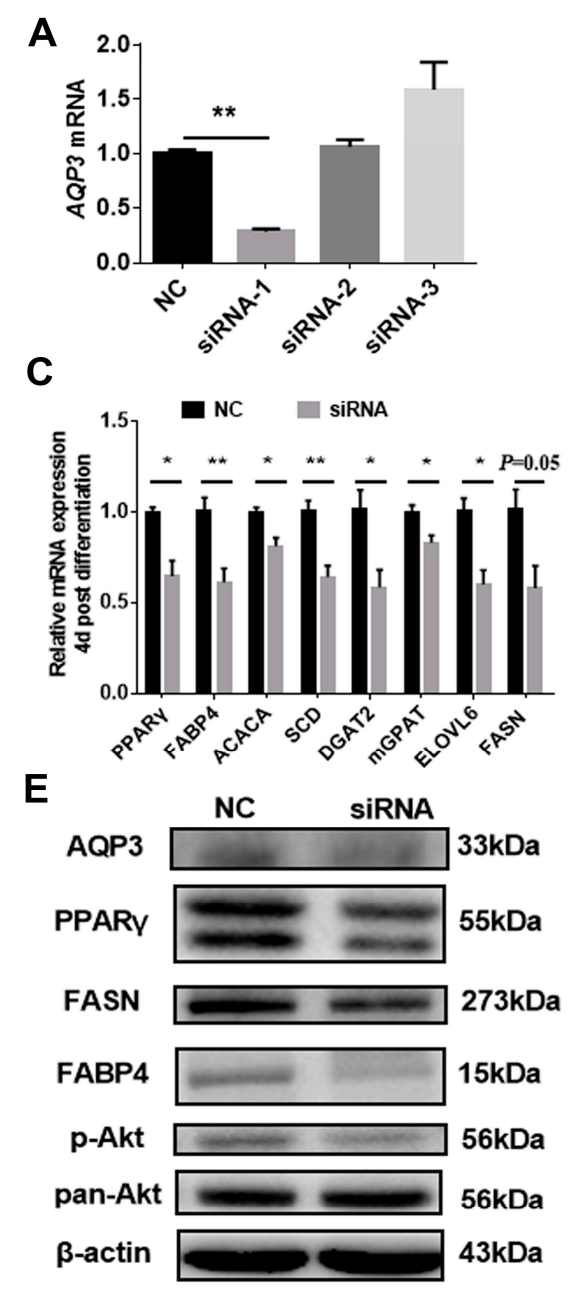

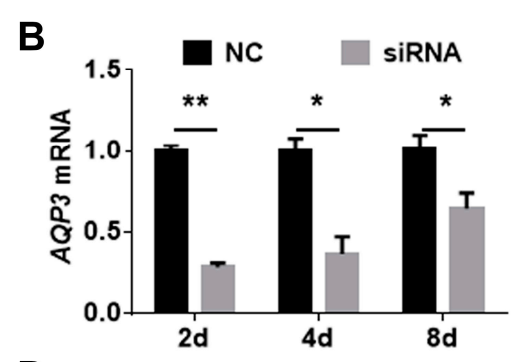

D

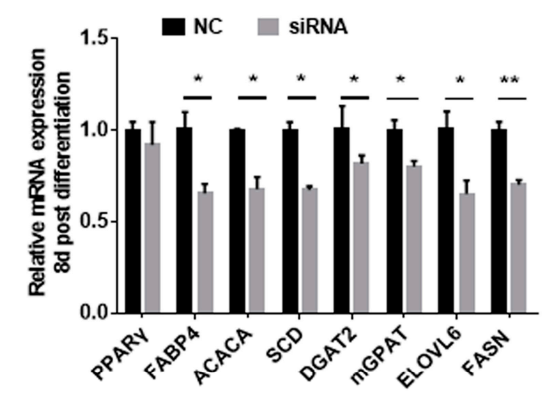

$\mathbf{F}$

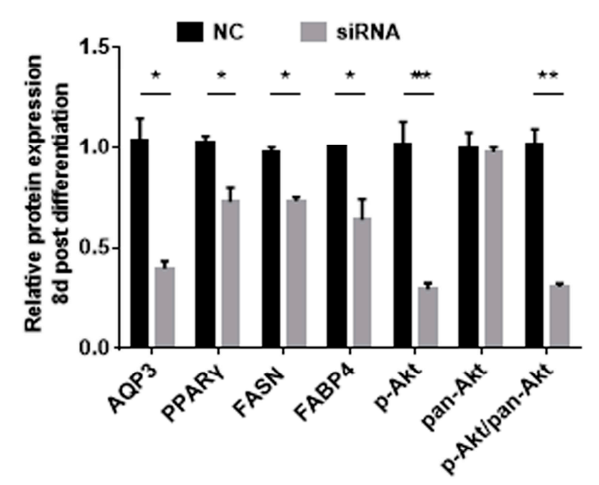

Figure 3. Cont. 
G

$\mathrm{NC}$

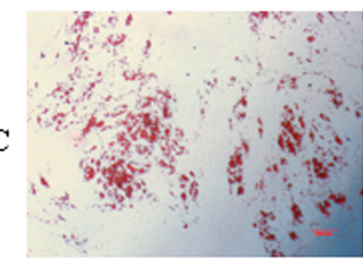

SiRNA

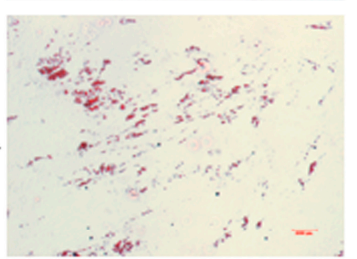

H

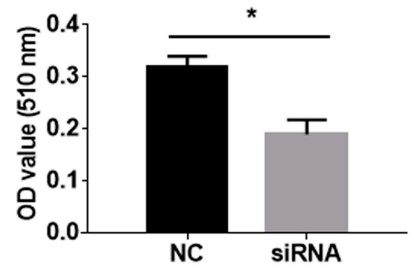

Figure 3. AQP3 silence repressed adipogenic differentiation in porcine intramuscular adipocytes. Cells were transfected with 3 candidate siRNAs targeting AQP3 when reaching $70-80 \%$ confluence, and only siRNA-1 could decrease AQP3 transcripts by $70 \%$ (A) $24 \mathrm{~h}$ post-transfection, and it also significantly repressed AQP3 expression $48 \mathrm{~h}, 4 \mathrm{~d}$, and $8 \mathrm{~d}$ post-differentiation (B). Expression of adipogenic and lipogenic genes $4 \mathrm{~d}$ and $8 \mathrm{~d}$ post-differentiation was detected by RT-qPCR, using $\beta$-actin as reference gene (C). Expression of adipogenesis-related genes $8 \mathrm{~d}$ post-differentiation was detected by Western blot (D). Western blot images (E) and gray analysis statistics (F) of PPAR $\gamma$, aP2, FASN, and Akt in PIPAs. Lipid accumulation was tested by Oil Red $\mathrm{O}$ staining $(\mathbf{G})$ and quantified by isopropanol extraction $(\mathbf{H})$. $n=3 ;{ }^{*} p<0.05, * * p<0.01$

\subsection{AQP3 Deletion Inhibits Proliferation}

AQP3 siRNA could significantly downregulate AQP3 mRNA expression in the proliferating porcine intramuscular preadipocytes $24 \mathrm{~h}$ post-transfection (Figure $4 \mathrm{~A}$ ), indicating that this siRNA can be used to inhibit the expression of AQP3 during the proliferation phase. The results of RT-qPCR showed that siRNA repressed the expression of cyclin B, cyclin D, cyclin E, and CDK4 mRNAs $48 \mathrm{~h}$ post-transfection (Figure 4B). Consistently, cyclin B, cyclin D, and proliferating cell nuclear antigen (PCNA) were significantly repressed by AQP3 siRNA at the protein level too (Figure 4C,D). Additionally, transfection of AQP3 siRNA significantly reduced the ratio of EdU-positive cells (Figure 4E,F) and cell viability (Figure $4 \mathrm{G}$ ). In summary, the above results show that during the proliferation phase, AQP3 exerts this effect to promote cell proliferation.

A
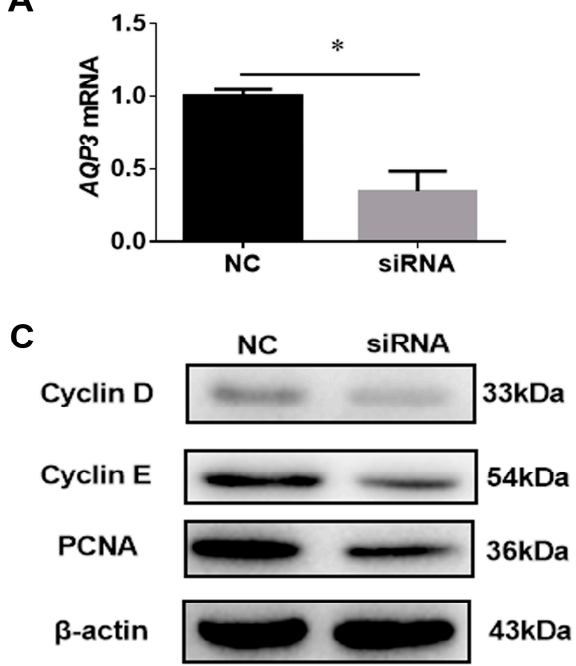

B
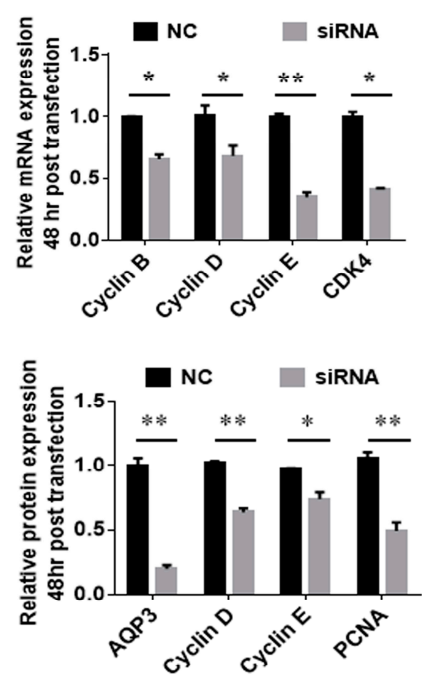

Figure 4. Cont. 
E
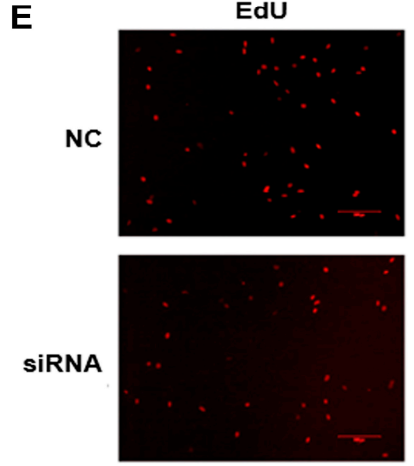

$\mathbf{F}$

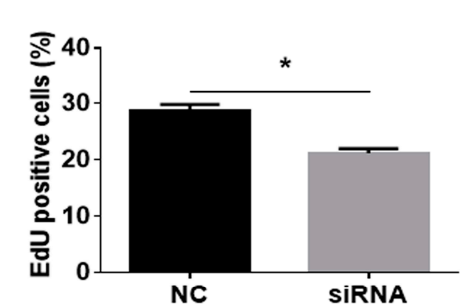

DAPI
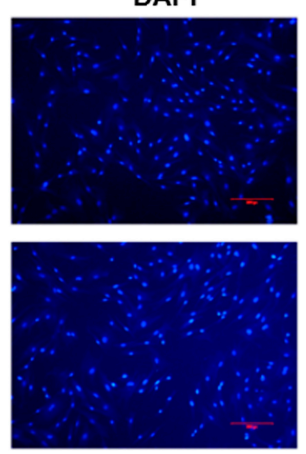

G
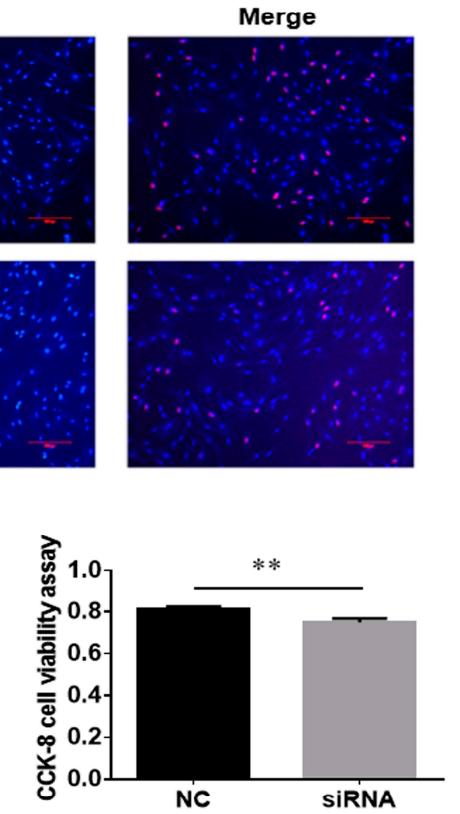

Figure 4. Knockdown of AQP3 inhibited the proliferation of porcine intramuscular adipocytes. Cells were transfected with AQP3 siRNA at 40-50\% confluence, and the interference effect was over 70\% $24 \mathrm{~h}$ post-transfection (A). Cell cycle genes were analyzed by RT-qPCR (B) and Western blot (C,D). EdU staining was captured (E) and EdU-positive cells were counted to monitor the proliferation of cells (F). CCK-8 was adopted to check cell viability (G). $n=3$. CDK4, cyclin-dependent kinase 4; PCNA, proliferating cell nuclear antigen; DAPI, $4^{\prime}, 6$-diamidino-2-phenylindole; ${ }^{*} p<0.05,{ }^{* *} p<0.01$.

\section{Discussion}

The relationship between $\mathrm{AQP} 3$ and adipose tissues or cells has been ignored for a long time, and its expression in adipose tissues or adipocytes remains ambiguous. In pioneering work, AQP3 mRNA was undetectable in adipose tissues of Meishan pigs by semi-quantitative RT-PCR [28]. Meanwhile, there were other studies that did not support the presence of AQP3 in mouse [29,30] or human adipose tissue [31]. However, mRNAs and proteins of AQP3 were later detected in human stroma vascular fraction of omental, subcutaneous adipocyte tissue, and also in freshly isolated adipocytes [6]. Additionally, the expression of AQP3 was confirmed in murine 3T3-L1 cell line [32,33]. The inconsistent reports might be due to the relatively lower expression levels of AQP3 in mature adipose tissues [6,12].

In the present study, RT-qPCR and Western blot uncovered the upregulation of AQP3 during the process of adipogenic differentiation, indicating that AQP3 may also play a regulatory role in intramuscular adipocytes. Furthermore, AQP3 knockdown by siRNA leads to reduced expression of adipogenic and lipogenic genes and defects of TG storage in porcine intramuscular preadipocytes. After AQP3 was silenced, the expression of the classic adipogenic factor PPAR $\gamma$ was significantly inhibited. PPAR $\gamma$ is an indispensable transcription factor for adipocyte differentiation [34], and a previous study has shown that AQP3 is the target of PPAR $\gamma$ in murine adipose cell line [35] and hepatic stellate cells [36]. The level of phosphorylation of AKT was also decreased, which indicates that the downstream signal of the classic insulin signaling pathway is weakened. At the same time, the expression levels of other adipogenic marker genes aP2, ACACA, etc. were also decreased, indicating that the silencing of AQP3 inhibits the adipogenic differentiation of porcine intramuscular preadipocytes from the overall gene expression level. A previous study has also shown that AQP3 is more permeable to glycerol compared with water [14], and AQP3 was increased in LPS-induced adipogenesis [32] and triglyceride sedimentation [37]. A combination of our and others' work supports a pivotal role of AQP3 in lipid accumulation in adipocytes.

Besides, AQP3 also has the potential to regulate cell proliferation. Accumulated studies have shown that AQPs are involved in tumor metastasis [15]. AQP3 and AQP5 can be used as new markers 
for breast cancer [38]. Another study showed that overexpression of AQP3 in mammalian cells can promote cell proliferation efficiency and cell cycle transition [39]. In our study, AQP3 siRNA weakened the proliferation ability of porcine intramuscular preadipocytes, which was reflected in the downregulation of genes such as cyclin B and cyclin D, and a decrease in the number of EDU ${ }^{+}$cells. This shows that AQP3 can not only regulate cell proliferation in cancer cells, but also in intramuscular preadipocytes. For IMF, the proliferation and differentiation of adipocytes are two very important fat deposition processes [40]. AQP3 shows regulatory capacity in both proliferation and differentiation, which further illustrates that AQP3 is a key gene for adipocytes.

In the AQPs family, AQP7 can promote the loss of glycerol from adipocytes and inhibit the accumulation of fat, while AQP9 is responsible for the uptake of glycerin [41]. Additionally, the weakening of AQP5 can inhibit the late adipogenesis of 3T3-L1 cells [42]. Compared with other $\mathrm{AQP}$ genes, the present study proves that AQP3 can regulate fat deposition in two ways, namely adipocyte proliferation and differentiation, revealing that AQP3 is likely to be a new key factor in regulating fat deposition, which supplements the regulation of adipocytes by AQPs.

\section{Conclusions}

Collectively, our work has identified AQP3 as a novel and essential modulator in proliferation, differentiation, and lipid accumulation in intramuscular adipocytes, providing a new theoretical basis for the regulation of skeletal muscle ectopic fat deposition. This conclusion may be due to the involvement of AQP3 in the transport of glycerol, but further research is needed.

Author Contributions: Wrote this paper and analyzed the data: X.W.; performed the cell culture and cell-based analysis: J.Y. and Y.Y.; gave critical suggestions about the experimental design and manuscript preparation: X.S. and G.Y.; designed the experiment and revised the manuscript: X.L. All authors have read and agreed to the published version of the manuscript.

Funding: This study was supported by Major Projects for Genetically Modified Organisms Breeding (2016ZX08006003) and National Natural Science Foundation (31501925).

Conflicts of Interest: The authors declare no conflict of interest.

\section{References}

1. Hausman, G.J.; Basu, U.; Du, M.; Fernyhough-Culver, M.; Dodson, M.V. Intermuscular and intramuscular adipose tissues: Bad vs. good adipose tissues. Adipocyte 2014, 3, 242-255. [CrossRef] [PubMed]

2. Listrat, A.; Lebret, B.; Louveau, I.; Astruc, T.; Bonnet, M.; Lefaucheur, L.; Picard, B.; Bugeon, J. How Muscle Structure and Composition Influence Meat and Flesh Quality. Scientific World J. 2016, 2016, 3182746. [CrossRef]

3. Frank, D.; Joo, S.T.; Warner, R. Consumer Acceptability of Intramuscular Fat. Korean J. Food Sci. Anim. Resour. 2016, 36, 699-708. [CrossRef] [PubMed]

4. Da Silva, I.V.; Soveral, G. Aquaporins in Obesity. Adv. Exp. Med. Biol. 2017, 969, 227-238. [CrossRef] [PubMed]

5. Iena, F.M.; Lebeck, J. Implications of Aquaglyceroporin 7 in Energy Metabolism. Int. J. Mol. Sci. 2018, 19, 154. [CrossRef]

6. Rodriguez, A.; Catalan, V.; Gomez-Ambrosi, J.; Garcia-Navarro, S.; Rotellar, F.; Valenti, V.; Silva, C.; Gil, M.J.; Salvador, J.; Burrell, M.A.; et al. Insulin- and leptin-mediated control of aquaglyceroporins in human adipocytes and hepatocytes is mediated via the PI3K/Akt/mTOR signaling cascade. J. Clin. Endocrinol. Metab. 2011, 96, E586-E597. [CrossRef]

7. Laforenza, U.; Scaffino, M.F.; Gastaldi, G. Aquaporin-10 represents an alternative pathway for glycerol efflux from human adipocytes. PLoS ONE 2013, 8, e54474. [CrossRef]

8. Madeira, A.; de Almeida, A.; de Graaf, C.; Camps, M.; Zorzano, A.; Moura, T.F.; Casini, A.; Soveral, G. A gold coordination compound as a chemical probe to unravel aquaporin-7 function. Chembiochem 2014, 15, 1487-1494. [CrossRef]

9. Rodriguez, R.A.; Liang, H.; Chen, L.Y.; Plascencia-Villa, G.; Perry, G. Single-channel permeability and glycerol affinity of human aquaglyceroporin AQP3. Biochim. Biophys. Acta Biomembr. 2019, 1861, 768-775. [CrossRef] 
10. Tardelli, M.; Claudel, T.; Bruschi, F.V.; Moreno-Viedma, V.; Trauner, M. Adiponectin regulates AQP3 via PPARalpha in human hepatic stellate cells. Biochem. Biophys. Res. Commun. 2017, 490, 51-54. [CrossRef]

11. Rodriguez, A.; Moreno, N.R.; Balaguer, I.; Mendez-Gimenez, L.; Becerril, S.; Catalan, V.; Gomez-Ambrosi, J.; Portincasa, P.; Calamita, G.; Soveral, G.; et al. Leptin administration restores the altered adipose and hepatic expression of aquaglyceroporins improving the non-alcoholic fatty liver of ob/ob mice. Sci. Rep. 2015, 5, 12067. [CrossRef] [PubMed]

12. Marzi, C.; Holdt, L.M.; Fiorito, G.; Tsai, P.C.; Kretschmer, A.; Wahl, S.; Guarrera, S.; Teupser, D.; Spector, T.D.; Iacoviello, L.; et al. Epigenetic Signatures at AQP3 and $\mathrm{SOCS}_{3}$ Engage in Low-Grade Inflammation across Different Tissues. PLoS ONE 2016, 11, e0166015. [CrossRef] [PubMed]

13. Yang, J. Identification of Key Genes for Differential Deposition and Functional Analysis of AQP3 in Porcine Intramusclar Fat. Master's Thesis, NWAFU, Yangling, China, May 2018.

14. Arif, M.; Kitchen, P.; Conner, M.T.; Hill, E.J.; Nagel, D.; Bill, R.M.; Dunmore, S.J.; Armesilla, A.L.; Gross, S.; Carmichael, A.R.; et al. Downregulation of aquaporin 3 inhibits cellular proliferation, migration and invasion in the MDA-MB-231 breast cancer cell line. Oncol. Lett. 2018, 16, 713-720. [CrossRef] [PubMed]

15. Marlar, S.; Jensen, H.H.; Login, F.H.; Nejsum, L.N. Aquaporin-3 in Cancer. Int. J. Mol. Sci. 2017, $18,2106$. [CrossRef]

16. Wang, X.; Tao, C.; Yuan, C.; Ren, J.; Yang, M.; Ying, H. AQP3 small interfering RNA and PLD2 small interfering RNA inhibit the proliferation and promote the apoptosis of squamous cell carcinoma. Mol. Med. Rep. 2017, 16, 1964-1972. [CrossRef]

17. Xiong, G.; Chen, X.; Zhang, Q.; Fang, Y.; Chen, W.; Li, C.; Zhang, J. RNA interference influenced the proliferation and invasion of XWLC-05 lung cancer cells through inhibiting aquaporin 3. Biochem. Biophys. Res. Commun. 2017, 485, 627-634. [CrossRef] [PubMed]

18. Li, Z.; Li, B.; Zhang, L.; Chen, L.; Sun, G.; Zhang, Q.; Wang, J.; Zhi, X.; Wang, L.; Xu, Z.; et al. The proliferation impairment induced by AQP3 deficiency is the result of glycerol uptake and metabolism inhibition in gastric cancer cells. Tumour Biol. 2016, 37, 9169-9179. [CrossRef]

19. Chen, L.; Li, Z.; Zhang, Q.; Wei, S.; Li, B.; Zhang, X.; Zhang, L.; Li, Q.; Xu, H.; Xu, Z. Silencing of AQP3 induces apoptosis of gastric cancer cells via downregulation of glycerol intake and downstream inhibition of lipogenesis and autophagy. OncoTargets Ther. 2017, 10, 2791-2804. [CrossRef]

20. Li, X.; Huang, K.; Chen, F.; Li, W.; Sun, S.; Shi, X.E.; Yang, G. Verification of suitable and reliable reference genes for quantitative real-time PCR during adipogenic differentiation in porcine intramuscular stromal-vascular cells. Animal 2016, 10, 947-952. [CrossRef]

21. He, L.; Huang, N.; Li, H.; Tian, J.; Zhou, X.; Li, T.; Yao, K.; Wu, G.; Yin, Y. AMPK/ $\alpha$-Ketoglutarate Axis Regulates Intestinal Water and Ion Homeostasis in Young Pigs. J. Agric. Food Chem. 2017, 65, 2287-2298. [CrossRef]

22. Liu, J.B.; Chen, D.W.; Yu, B.; Mao, X.B. Effect of maternal folic acid supplementation on hepatic one-carbon unit associated gene expressions in newborn piglets. Mol. Biol. Rep. 2011, 38, 3849-3856. [CrossRef] [PubMed]

23. Cheng, J.; Song, Z.Y.; Pu, L.; Yang, H.; Zheng, J.M.; Zhang, Z.Y.; Shi, X.E.; Yang, G.S. Retinol binding protein 4 affects the adipogenesis of porcine preadipocytes through insulin signaling pathways. Biochem. Cell Biol. 2013, 91, 236-243. [CrossRef] [PubMed]

24. Lv, Y.; Zhang, S.; Guan, W.; Chen, F.; Zhang, Y.; Chen, J.; Liu, Y. Metabolic transition of milk triacylglycerol synthesis in response to varying levels of palmitate in porcine mammary epithelial cells. Genes Nutr. 2018, 13, 18. [CrossRef]

25. Yang, Y.; Ju, D.; Zhang, M.; Yang, G. Interleukin-6 stimulates lipolysis in porcine adipocytes. Endocrine 2008, 33, 261-269. [CrossRef] [PubMed]

26. Zhen, Y.H.; Wang, L.; Riaz, H.; Wu, J.B.; Yuan, Y.F.; Han, L.; Wang, Y.L.; Zhao, Y.; Dan, Y.; Huo, L.J. Knockdown of CEBPbeta by RNAi in porcine granulosa cells resulted in $\mathrm{S}$ phase cell cycle arrest and decreased progesterone and estradiol synthesis. J. Steroid. Biochem. Mol. Biol. 2014, 143, 90-98. [CrossRef] [PubMed]

27. Dozois, C.M.; Oswald, E.; Gautier, N.; Serthelon, J.P.; Fairbrother, J.M.; Oswald, I.P. A reverse transcription-polymerase chain reaction method to analyze porcine cytokine gene expression. Vet. Immunol. Immunopathol. 1997, 58, 287-300. [CrossRef] 
28. Li, X.; Lei, T.; Xia, T.; Chen, X.; Feng, S.; Chen, H.; Chen, Z.; Peng, Y.; Yang, Z. Molecular characterization, chromosomal and expression patterns of three aquaglyceroporins (AQP3, 7, 9) from pig. Comp. Biochem. Physiol. B Biochem. Mol. Biol. 2008, 149, 468-476. [CrossRef]

29. Kishida, K.; Kuriyama, H.; Funahashi, T.; Shimomura, I.; Kihara, S.; Ouchi, N.; Nishida, M.; Nishizawa, H.; Matsuda, M.; Takahashi, M.; et al. Aquaporin adipose, a putative glycerol channel in adipocytes. J. Biol. Chem. 2000, 275, 20896-20902. [CrossRef]

30. Maeda, N.; Funahashi, T.; Hibuse, T.; Nagasawa, A.; Kishida, K.; Kuriyama, H.; Nakamura, T.; Kihara, S.; Shimomura, I.; Matsuzawa, Y. Adaptation to fasting by glycerol transport through aquaporin 7 in adipose tissue. Proc. Natl. Acad. Sci. USA 2004, 101, 17801-17806. [CrossRef]

31. Miranda, M.; Escote, X.; Ceperuelo-Mallafre, V.; Alcaide, M.J.; Simon, I.; Vilarrasa, N.; Wabitsch, M.; Vendrell, J. Paired subcutaneous and visceral adipose tissue aquaporin-7 expression in human obesity and type 2 diabetes: Differences and similarities between depots. J. Clin. Endocrinol. Metab. 2010, 95, 3470-3479. [CrossRef]

32. Chiadak, J.D.; Arsenijevic, T.; Gregoire, F.; Bolaky, N.; Delforge, V.; Perret, J.; Delporte, C. Involvement of JNK/NFkappaB Signaling Pathways in the Lipopolysaccharide-Induced Modulation of Aquaglyceroporin Expression in 3T3-L1 Cells Differentiated into Adipocytes. Int. J. Mol. Sci. 2016, 17, 1742. [CrossRef] [PubMed]

33. Choudhary, V.; Olala, L.O.; Kagha, K.; Pan, Z.Q.; Chen, X.; Yang, R.; Cline, A.; Helwa, I.; Marshall, L.; Kaddour-Djebbar, I.; et al. Regulation of the Glycerol Transporter, Aquaporin-3, by Histone Deacetylase-3 and p53 in Keratinocytes. J. Investig. Dermatol. 2017, 137, 1935-1944. [CrossRef] [PubMed]

34. Janani, C.; Ranjitha Kumari, B.D. PPAR $\gamma$ gene-A review. Diabetes Metab. Syndr. 2015, 9, 46-50. [CrossRef] [PubMed]

35. Kishida, K.; Shimomura, I.; Nishizawa, H.; Maeda, N.; Kuriyama, H.; Kondo, H.; Matsuda, M.; Nagaretani, H.; Ouchi, N.; Hotta, K.; et al. Enhancement of the aquaporin adipose gene expression by a peroxisome proliferator-activated receptor $\gamma$. J. Biol. Chem. 2001, 276, 48572-48579. [CrossRef] [PubMed]

36. Tardelli, M.; Bruschi, F.V.; Claudel, T.; Moreno-Viedma, V.; Halilbasic, E.; Marra, F.; Herac, M.; Stulnig, T.M.; Trauner, M. AQP3 is regulated by PPARgamma and JNK in hepatic stellate cells carrying PNPLA3 I148M. Sci. Rep. 2017, 7, 14661. [CrossRef] [PubMed]

37. Chiadak, J.D.; Gena, P.; Gregoire, F.; Bolaky, N.; Delforge, V.; Perret, J.; Calamita, G.; Delporte, C. Lipopolysaccharide Modifies Glycerol Permeability and Metabolism in 3T3-L1 Adipocytes. Int. J. Mol. Sci. 2017, 18, 2566. [CrossRef]

38. Zhu, Z.; Jiao, L.; Li, T.; Wang, H.; Wei, W.; Qian, H. Expression of AQP3 and AQP5 as a prognostic marker in triple-negative breast cancer. Oncol. Lett. 2018, 16, 2661-2667. [CrossRef]

39. Galan-Cobo, A.; Ramirez-Lorca, R.; Serna, A.; Echevarria, M. Overexpression of AQP3 Modifies the Cell Cycle and the Proliferation Rate of Mammalian Cells in Culture. PLoS ONE 2015, 10, e0137692. [CrossRef]

40. Sarantopoulos, C.N.; Banyard, D.A.; Ziegler, M.E.; Sun, B.; Shaterian, A.; Widgerow, A.D. Elucidating the Preadipocyte and Its Role in Adipocyte Formation: A Comprehensive Review. Stem. Cell Rev. Rep. 2018, 14, 27-42. [CrossRef]

41. Lebeck, J. Metabolic impact of the glycerol channels AQP7 and AQP9 in adipose tissue and liver. J. Mol. Endocrinol. 2014, 52, R165-R178. [CrossRef]

42. Madeira, A.; Mosca, A.F.; Moura, T.F.; Soveral, G. Aquaporin-5 is expressed in adipocytes with implications in adipose differentiation. IUBMB Life 2015, 67, 54-60. [CrossRef] [PubMed]

(C) 2020 by the authors. Licensee MDPI, Basel, Switzerland. This article is an open access article distributed under the terms and conditions of the Creative Commons Attribution (CC BY) license (http://creativecommons.org/licenses/by/4.0/). 